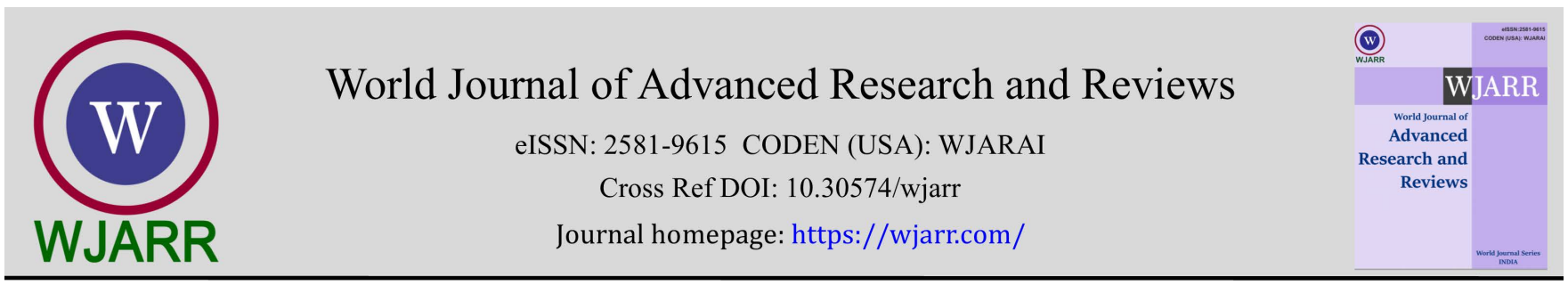

(RESEARCH ARTiClE)

\title{
Variations of prothrombin time among ABO blood groups in healthy adults
}

\author{
Afrina Binte Azad 1, *, Qazi Shamima Akhter 2, Mohammad Aminul Islam 3, Farzana Yeasmin Mukta 4 , Lily \\ Afroz ${ }^{5}$, Khushbun Nahar Layla ${ }^{6}$, Syed Tasin Bin Shahid ${ }^{7}$, Shamanta Islam ${ }^{8}$ and A.Z.M. Adnan ${ }^{9}$
}

${ }^{1}$ Department of Physiotherapy, National Institute of Traumatology and Orthopaedic Rehabilitation, Dhaka, Bangladesh.

2 Department of Physiology, Dhaka Medical College, Dhaka, Bangladesh.

${ }^{3}$ Department of Orthopaedics, National Institute of Traumatology andOrthopaedics Rehabilitation, Dhaka, Bangladesh.

${ }^{4}$ Department of Cardiology, Kurmitola General Hospital, Dhaka, Bangladesh.

${ }^{5}$ Department of Physiology, Mymensingh Medical College and Hospital, Mymensingh, Bangladesh.

${ }^{6}$ Department of Physiology, Ibrahim Medical College and Hospital, Dhaka, Bangladesh.

${ }^{7}$ Epsom and st helier nhs trust, Epsom, London, UK.

${ }^{8}$ Bhairab Upazila Health Complex, Kishoreganj, Bangladesh.

${ }^{9}$ Department of Nephrology, Chattogram Medical College and Hospital, Chattogram, Bangladesh.

World Journal of Advanced Research and Reviews, 2021, 11(03), 429-435

Publication history: Received on 23 August 2021; revised on 26 September 2021; accepted on 28 September 2021

Article DOI: https://doi.org/10.30574/wjarr.2021.11.3.0484

\begin{abstract}
Background and objectives: ABO blood group distribution defers with racial and geographic variations. They are related with diseases like cardiovascular diseases, cerebral thromboembolism. Prothrombin time may varies among ABO blood group system which may increase the future risk of thrombosis. The present study is to assess prothrombin time among ABO blood groups in healthy adults.
\end{abstract}

Materials and methods: A prospective type of analytical cross-sectional study was conducted in the Department of Physiology, Dhaka Medical College, Dhaka from July 2019 to June 2020. After obtaining ethical clearance, a total 190 healthy adults were selected from different areas of Dhaka city based on inclusion and exclusion criteria, with age ranging from 18-45 years. The subjects were interviewed and detailed history regarding personal, family, medical and drug were taken. Prior to sample collection, informed written consent was taken from the participants. Individuals of blood group A was selected as group A, blood group B as group B, blood group AB as group AB and blood group 0 as group 0. Prothrombin time was measured in the Department of Hematology and BMT Unit, Dhaka Medical College Hospital, Dhaka. Blood grouping was done in the Department of Physiology, Dhaka Medical College, Dhaka.For statistical analysis, One way ANOVA followed by Bonferroni test were considered using SPSS 25.0 version.

Results: In this study, blood group B was most common (33.2\%). Prothrombin time was lower in blood group A $(12.93 \pm 0.30 \mathrm{sec}), \mathrm{B}(12.92 \pm 0.61 \mathrm{sec}), \mathrm{AB}(12.98 \pm 0.54 \mathrm{sec})$ than blood group $0(13.08 \pm 0.39 \mathrm{sec})$ which was not statistically significant.

Conclusion: It can be concluded that blood group A, B, AB individuals may have more chance of thrombosis due to lower prothrombin time than blood group 0 individuals.

Keywords: ABO blood groups; Prothrombin time; Healthy adults; Individuals

\footnotetext{
${ }^{*}$ Corresponding author: Afrina Binte Azad

Lecturer, Department of Physiotherapy, National Institute of Traumatology and Orthopaedic Rehabilitation, Dhaka, Bangladesh. 


\section{Introduction}

ABO blood groups were discovered by Karl Landsteiner. It was the landmark for modern practice of transfusion medicine [1]. The incidence of $\mathrm{ABO}$ and $\mathrm{Rh}$ blood groups vary markedly with geographic and racial variations. In Caucasians of America, the predominant blood group is the group $\mathrm{O}(45 \%)$ followed by group A (41\%), B (10\%) and AB (4\%). Native American Indians belong almost to blood group 0.Among western Europeans, group 0 occurs in highest frequency (46\%) followed by group A (42\%), B (9\%) and AB (3\%). In eastern European, predominant blood group is the group B (40\%) [2]. In Australia and Britain, the commonest blood groups are group $\mathrm{O}$ and $\mathrm{A}$ followed by group B and $\mathrm{AB}$. In Indo-Pak sub-continent, group B and $\mathrm{O}$ occur in highest frequency [3]. In Bangladesh, the commonest blood group is blood group B (34.4\%) followed by group $0(30.4 \%)$, A (26.7\%) and AB (8.6\%). Distribution of Rh positive blood group is $97.4 \%$ and $\mathrm{Rh}$ negative blood is $2.6 \%$ [4].

Determination of blood group is very essential as it plays an important role in genetics, blood transfusion, forensic medicine and may be related with diseases like duodenal ulcer, diabetes mellitus [5]. Blood group 0 has a strong association with duodenal ulcer [6].

Prothrombin time is the commonly used screening tests of coagulation. This test assesses the disorders in extrinsic clotting pathways. Abnormal result is usually seen when factor I, II, V, VII, X are deficient. Prothrombin time testing first emerged in the early 1900s using manual coagulation test methods. Now a day, it has been measured with commercially available reagents and automated instrumentation $[7,8]$.

Different researchers of various country performed studies to find out the relation of ABO blood groups with prothrombin time. Okeke et al. (2018) found that prothrombin time was significantly prolonged in blood group A than blood group $\mathrm{O}, \mathrm{B}$ and $\mathrm{AB}[8]$. On the other hand, some researchers observed no significant difference of prothrombin time level among ABO blood groups [9].

The present study was undertaken to assess the variations of prothrombin time among ABO blood groups in healthy adults and to identify those blood groups which may have more chance of thrombotic diseases. This study also aimed to bring awareness to prevent thrombotic diseases related morbidity.

\section{Material and methods}

\subsection{Study population and sample size}

This prospective type of analytical cross-sectional study was carried out in the Department of Physiology, Dhaka Medical College, Dhaka from July 2019 to June 2020. A total of 190 Bangladeshi healthy adult male and female, aged 18-45 years were selected from different areas of Dhaka city for this study.

\subsection{Grouping of the subjects}

Sample size was divided into four groups on the basis of ABO blood groups.

Group A: 45 healthy adults of blood group A.

Group B: 63 healthy adults of blood group B.

Group AB: 30 healthy adults of blood group AB.

Group 0: 52 healthy adults of blood group 0.

\subsection{Procedure methodology}

The research work was carried out after obtaining ethical clearance. Subjects from different areas of Dhaka city were contacted either by phone or in person and details of the study procedure, the nature, purpose and benefit of the study was explained to each subject. They were asked for their voluntary participation. Subjects who were interested to take part in the study were requested to attend the Department of Physiology, Dhaka Medical College, Dhaka. When they came, they were interviewed and detail history regarding personal, family, medical and drug history were taken. Anthropometric measurement of the subjects were done and blood pressure were measured. All the informations were recorded in a prefixed data collection form. Prior to blood sample collection, informed written consent was taken from 
the participants. Prothrombin time was estimated in the Department of Haematology \& BMT Unit, Dhaka Medical College Hospital, Dhaka by using Sysmex fully automated coagulation analyzer machine. Blood grouping was done in the Department of Physiology, Dhaka Medical College, Dhaka on the basis of presence or the absence of agglutination by slide method. Subjects who were unable to come to Dhaka Medical College, their blood samples were collected from their respective work station or from their home. These blood samples were carried in a cool box to the respective department of Dhaka Medical College Hospital, Dhaka for investigations. Study subjects were grouped into four groups on the basis of blood grouping. Blood sample collection was continued until fulfillment of minimum 30 subjects in each group. To fulfill minimum 30 subjects in each group, equal number of study subjects could not be maintained. A total 190 subjects were included in this study. Out of them, 45 study subjects were included in group A, 63 study subjects were included in group B, 30 study subjects were included in group AB and 52 study subjects were included in group 0.

\subsection{Statistical analysis}

All the parameters were expressed as mean \pm SD (standard deviation) and range. One way ANOVA followed by Bonferroni test was performed to compare between groups. $p$ value $<0.05$ was accepted as level of significance. Statistical analysis was performed by using a computer based statistical program SPSS (Statistical Package for Social Science) version 25.0

\section{Results}

A total 190 healthy adults were included in this study. Out of them blood group A was found in 45 (23.7\%) subjects, blood group B was found in 63 (33.2\%) subjects, blood group AB was found in 30 (15.8\%) subjects and blood group 0 was found in 52 (27.4\%) subjects (Table 1 and Figure 1).

Table 1 Blood group distribution of the subjects $(\mathrm{N}=190)$

\begin{tabular}{|l|l|l|}
\hline Blood groups & Number & Frequency \\
\hline $\mathrm{A}$ & 45 & $23.7 \%$ \\
\hline $\mathrm{B}$ & 63 & $33.2 \%$ \\
\hline $\mathrm{AB}$ & 30 & $15.8 \%$ \\
\hline O & 52 & $27.4 \%$ \\
\hline Total & 190 & $100 \%$ \\
\hline
\end{tabular}

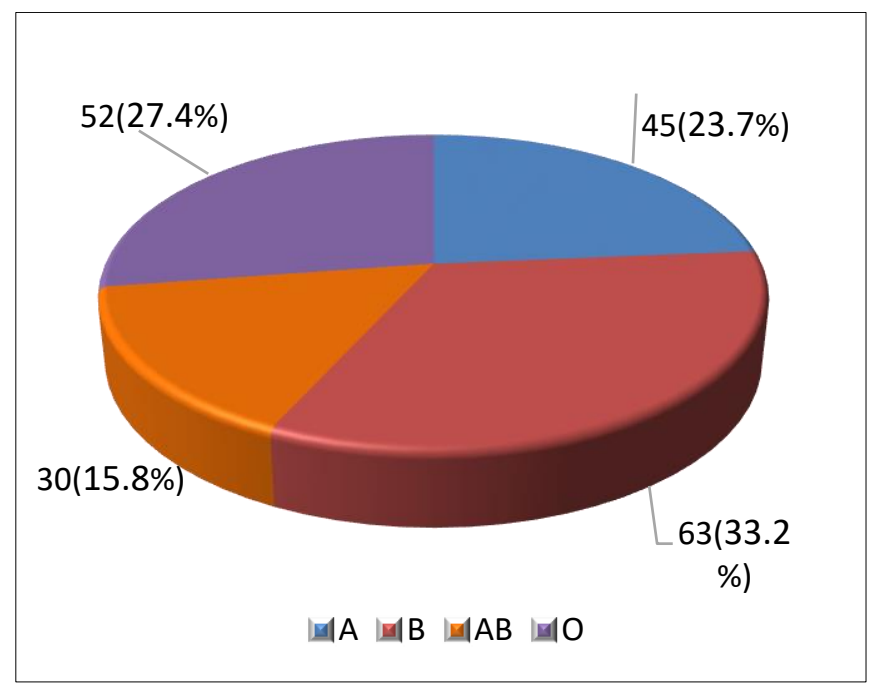

Figure 1 Distribution of study subjects according to blood groups (N=190). N : Total number of subjects; A : Blood group A; B :Blood group B; AB : Blood group AB; 0 : Blood group 0

The mean $( \pm \mathrm{SD})$ prothrombin time was $12.93 \pm 0.30 \mathrm{sec}, 12.92 \pm 0.61 \mathrm{sec}, 12.98 \pm 0.54 \mathrm{sec}, 13.08 \pm 0.39 \mathrm{sec}$ in group A, group $\mathrm{B}$, group $\mathrm{AB}$ and group 0 respectively. The mean difference among the groups were not statistically significant 
$(p=0.294)$. Group 0 individuals showed prolonged mean $( \pm \mathrm{SD})$ prothrombin time than group $\mathrm{A}, \mathrm{B}$ and $\mathrm{AB}$. But mean difference between group $\mathrm{A}$ and $\mathrm{B}, \mathrm{A}$ and $\mathrm{AB}, \mathrm{A}$ and $\mathrm{O}, \mathrm{B}$ and $\mathrm{AB}, \mathrm{B}$ and $\mathrm{O}, \mathrm{AB}$ and $\mathrm{O}$ was not significant $(p>0.05)$ regarding prothrombin time (Table 2 and Figure 2).

Table 2 Prothrombin time of the study subjects in different groups $(\mathrm{N}=190)$

\begin{tabular}{|c|c|c|c|c|}
\hline \multirow[t]{2}{*}{ Parameter } & \multicolumn{4}{|c|}{ Groups } \\
\hline & $\begin{array}{l}\text { Group A } \\
\left(n_{1}=45\right)\end{array}$ & $\begin{array}{l}\text { Group B } \\
\left(n_{2}=63\right)\end{array}$ & $\begin{array}{c}\text { Group AB } \\
\left(n_{3}=30\right)\end{array}$ & $\begin{array}{l}\text { Group 0 } \\
\left(n_{4}=52\right)\end{array}$ \\
\hline Prothrombin time (sec) & $12.93 \pm 0.30$ & $12.92 \pm 0.61$ & $12.98 \pm 0.54$ & $13.08 \pm 0.39$ \\
\hline Statistical analysis & \multicolumn{4}{|l|}{$p$-value } \\
\hline Groups & \multicolumn{4}{|c|}{ Prothrombin time } \\
\hline $\mathrm{A}$ vs $\mathrm{B}$ vs $\mathrm{AB}$ vs $\mathrm{O}$ & \multicolumn{4}{|c|}{0.294} \\
\hline$A$ vs $B$ & \multicolumn{4}{|c|}{1.000} \\
\hline$A$ vs $A B$ & \multicolumn{4}{|c|}{1.000} \\
\hline A vs 0 & \multicolumn{4}{|c|}{0.705} \\
\hline$B$ vs $A B$ & \multicolumn{4}{|c|}{1.000} \\
\hline B vs 0 & \multicolumn{4}{|c|}{0.475} \\
\hline $\mathrm{O}$ vs $\mathrm{AB}$ & \multicolumn{4}{|c|}{1.000} \\
\hline
\end{tabular}

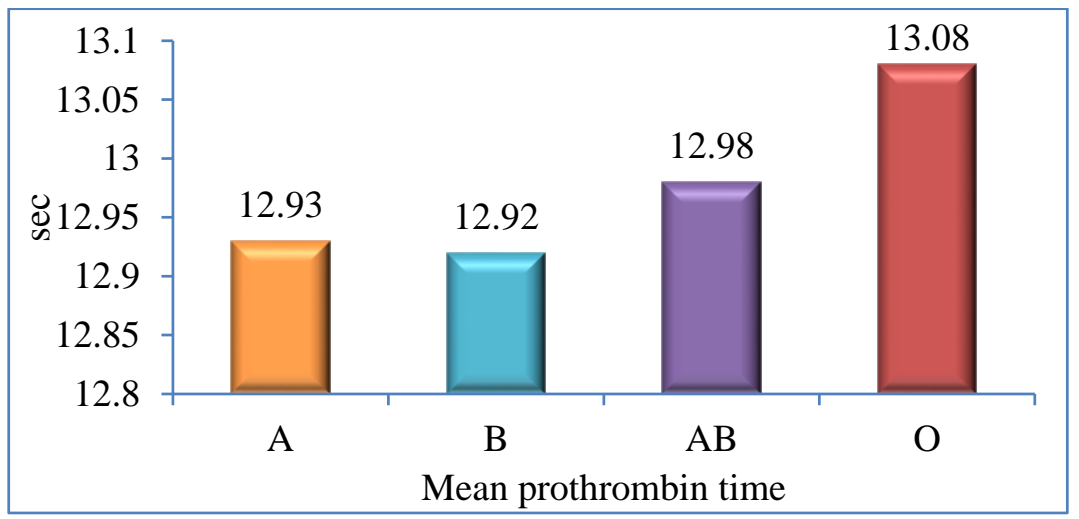

Figure 2 Mean prothrombin time of the study subjects in different groups $(\mathrm{N}=190)$. ). $\mathrm{N}$ : Total number of subjects; $\mathrm{A}$ : Blood group A; B :Blood group B; AB : Blood group AB; 0 : Blood group 0

Results were expressed as Mean \pm SD. One way ANOVA followed by Bonferroni test was performed to compare between groups. $\mathrm{N}=$ Total number of subjects, $\mathrm{n}_{1}=$ number of subjects in group $\mathrm{A}, \mathrm{n}_{2}=$ number of subjects in group $B, \mathrm{n}_{3}=$ number of subjects in group $\mathrm{AB}, \mathrm{n}_{4}=$ number of subjects in group 0 . The test of significance was calculated for all comparisons 
and $p$ value $<0.05$ was accepted as level of significance. Group A: blood group A, Group B: blood group B, Group AB: blood group AB, Group 0: blood group 0.

\section{Discussion}

The present study was undertaken to assess the variations of prothrombin time among different blood groups in healthy adults. For these purpose, a total number of 190 healthy adults with age ranging from 18 to 45 years were included in this study on the basis of inclusion and exclusion criteria. In present study, 45 subjects were selected in group A, 63 in group $B, 30$ in group $\mathrm{AB}$ and 52 subjects in group 0.

Table I and Figure 1 shows, the number and percent distribution of ABO blood groups of the study subjects. ABO blood groups revealed that group B was predominant with $33.2 \%$, followed by group 0 with $27.4 \%$, group A with $23.7 \%$ and group $\mathrm{AB}$ with $15.8 \%$. Almost similar types of results were observed by different researchers $[3,5,10]$.

On the other hand, some disagreements observed by various studies which might be due racial and geographic variation. Some researcher found that blood group 0 was the predominant blood group followed by blood group A, B and AB $[8,11,12]$. Agrawal et al. (2014) observed that blood group 0 was in highest frequency followed by blood group B, A and $\mathrm{AB}$ [13]. Some study showed that blood group A was the commonest blood group followed by blood group $\mathrm{B}, \mathrm{O}$ and $\mathrm{AB}$ [9].

Table II and Figure 2 shows, the mean prothrombin time of the subjects in all groups were within normal range. The prothrombin time in group 0 was higher than group $\mathrm{A}, \mathrm{B}$ and $\mathrm{AB}$. The mean difference among the groups were not statistically significant. Similarly, some researchers found no significant difference of prothrombin time among ABO blood groups $[9,14,15,16]$

Prothrombin time is the test of clotting function. It indicates the coagulation status of individuals. Prothrombin time is performed to test the extrinsic and common pathway of coagulation. Prothrombin time becomes prolonged when factor I, II, V, VII and X become deficient. ABO blood groups are related with von Willebrand factor and coagulation factor VIII but not related with factor I, II, V, VII and X. Thus prothrombin time is not differed among blood group A, B, AB and 0 $[17,7]$.

On the contrary of this study, Okeke et al. (2018) found that prothrombin time was significantly prolonged in blood group A than blood group $0, \mathrm{~B}$ and $\mathrm{AB}$. They suggested that prothrombin time level defers among different blood groups. This disagreement in findings might have occurred due to variation of coagulation factors of extrinsic pathway and common pathway of coagulation in different races [8]. El-Sayed and Amin (2015) showed that mean prothrombin time was significantly prolonged in blood group $\mathrm{AB}$ than blood group $\mathrm{A}, \mathrm{B}$ and $\mathrm{O}$. They selected hypertensive patients for that study but we selected healthy adults. This might be the cause of contrary in findings [18].

This present study had some limitations, Sample were taken purposively so that there may be chance of bias which can influence the results. More investigations like von Willebrand factor and coagulation factor I, VII, IX were not could not be meseared due to financial constrains, time and lack of availability.

\section{Conclusion}

After analyzing the results of the study, it can be concluded that blood group B is most common (33.2\%) among the study subjects. Blood group A, B, AB individuals may have more chance of thrombosis due to lower prothrombin time level than blood group $\mathrm{O}$ in this study.

\section{Compliance with ethical standards}

\section{Acknowledgments}

The authors acknowledge Department of Haematology \& BMT Unit, Dhaka Medical College Hospital, Dhaka for their kind cooperation.

\section{Disclosure of conflict of interest}

The author declares no conflict of interest. 


\section{Statement of ethical approval}

Ethical clearance of this study was obtained from concerned Departments, Research review committee and Ethical review committee of Dhaka Medical College, Dhaka.

\section{Statement of informed consent}

Informed consent was obtained from all individual participants included in the study.

\section{References}

[1] Schwarz HP, Dorner F. Karl Landsteiner and his major contributions to haematology. British Journal of Haematology, 2003; 121(4):556-565.

[2] Pramanik T, Pramanik S. Distribution of ABO and Rh blood groups in Nepalese medical students: A report. Eastern Mediterranean Health Journal, 2000; 6(1):156-158.

[3] Sultana R, Rahman Z, Helali AM, Yousuf R, Mustafa S, Salam A, Haque M. Study of ABO and Rh-D blood groups among the common people of Bangladesh. International Journal of Pharmacy and Pharmaceutical Sciences, 2013; 5(3):814-816.

[4] Dipta TF, Iqbal MR, Hossain AZ, Rahman MT, Chowdhury S. Distribution of Phenotypic and Genotypic Abo And Rhesus Blood Groups Among Bangladeshi Population. Ibrahim Medical College Journal, 2011; 5(2):59-62.

[5] Dibby HJ. Blood groups distribution \& its relationship with bleeding time and clotting time. AL- Qadisiya Medical Journal, 2014; 10(18):164-167.

[6] Akhtar MN, Butt AR, Tayyib M, Tasneem T. ABO Blood Group in Patients with Peptic Ulcer Disease: Association with Secretor Status. Annals of KEMU, 2003; 9(3):238-240.

[7] Ng VL. Prothrombin Time and Partial Thromboplastin Time Assay Considerations. Clinics in Laboratory Medicine, 2009; 29(2):253-263.

[8] Okeye CO, Okoro US, Babatunde A. Variations in activated partial thromboplastin time and prothrombin time in individuals of A, B, AB and O blood groups. Iraqi Journal of hematology, 2018; 7(2):85-89.

[9] Choi Q, Kim JE, Kim SY, Kyou SH, Kim HK. Influence of ABO type on global coagulation assay results: effect of coagulation factor VIII. Clinical Chemistry and Laboratory Medicine, 2014; 53(9):1425-1432.

[10] Iqbal M, Niazi A, Tahir M. Frequency of ABO and Rh blood groups in Healthy Donors. Journal of Rawalpindi Medical College, 2009; 13(2):92-94.

[11] Wang Z, Dou M, Du X, Ma L, Sun P, Cao H, Ye S, Jiang P, Liu F, Lin F, Zhang R, Li C. Influences of ABO blood group, age and gender on plasma coagulation factor VIII, fibrinogen, von Willebrand factor and ADAMTS13 levels in a Chinese population. Peer J,2017; 5(3):1-15.

[12] Ohira T, Cushman M, Tsai MY, Zhang Y, Heckbert SR, Zakai NA, Rosamond WD, Falsom AR. ABO blood Group, other risk factors and incidence of venous thromboembolism: the Longitudinal Investigation of Thromboembolism Etiology (LITE). Journal of Thrombosis and Haemostasis, 2007; 5(7):1455-1461.

[13] Agrawal A, Tiwari AK, Mehta N, Bhattacharya P, Wankhede R, Tulsiani S, Kamath S. ABO and Rh (D) group distribution and gene frequency; the first multicentric study in India.Asian Journal of Transfusion Science, 2014; 8(2):121-125.

[14] Khan ADY, Pujari AD. A comparative study of the variation in coagulation profile between different blood groups in ischemic heart disease patients and normal subjects. National Journal of Physiology, Pharmacy and Pharmacology, 2018; 8(11):1496-1499.

[15] Bahardoust M, Naghshin R, Mokhtare M, Hejrati A, Namdar P, Talebi A, Tavakoll T, Amiri H, Klapey SH.Association between ABO Blood Group and Clinical Outcome in Patients with Gastrointestinal Bleeding. Internal Medicine: Open Access, 2018; 8(1):1-6.

[16] Afifi OAH, Abdelsalam EMN, Makhlouf AAEAM, Ibrahim MAM. Evaluation of Coagulation Factors Activity in Different Types of Plasma Preparations. Indian Journal of Hematology and Blood Transfusion, 2019; 35(3):551556. 
[17] Suzuki S, Otsuka T, Sagara K, Semba H, Kono H, Matsuno S, Takai H, Kato Y, Uejima T, Oikawa Y, Nagashima K, Kirigaya H, Kunihara T, Yajima J, Sawada H, Aizawa T, Yamashita T. ABO Blood Type and Response of Activated Partial Thromboplastin Time to Dabigatran in Nonvalvular Atrial Fibrillation Patients. Circulation Journal, 2015; 79(10):2274-2277.

[18] El-Sayed MK, Amin H. ABO blood groups in correlation with hyperlipidemia, diabetes mellitus type II, and essential hypertension. Asian Journal of Pharmaceutical and Clinical Research, 2015; 8(5):236-243. 